Comparative Philosophy Volume 7, No. 1 (2016): 39-58

Open Access / ISSN 2151-6014

www.comparativephilosophy.org

\title{
SUNYATA IN THE WEST
}

\author{
DAVID GRANDY
}

\begin{abstract}
I argue that sunyata, or something like it, manifested itself in early Western thought. While Plato and Aristotle resisted emptiness or nothingness, they nevertheless felt themselves obliged to venture close to its edge in order to ground their explanations of changing reality to unchanging principles. These principles (Plato's receptacle and Aristotle's prime matter) embody much of the indeterminancy long associated with the Mahayana understanding of sunyata. Although their function was to enable lasting (static) explanations of reality by putting change out of play, they themselves shade off toward a featureless being evocative of non-being. Moving along a somewhat different track, Greek atomists embraced emptiness (or void) so as to permit self-existent, fully self-contained atoms to move about. In their system, non-being, a foundational principle of reality, paradoxically coexists with being. Interestingly, modern science has undone the self-containment of atoms-emptied them of properties once thought to be innate-and thereby removed yet another Western safeguard against change. It seems that change cannot be put out of play, though it does slope off toward sunyata-like emptiness.
\end{abstract}

Keywords: Sunyata, Plato's Receptacle, Aristotle's Prime Matter, Atomism, Nagarjuna

It is all but axiomatic that while Eastern thinkers accepted the idea of emptiness or nothingness without too much difficulty, Western thinkers generally found reasons to reject it. In Western antiquity Parmenides, Plato, and Aristotle are notably associated with the thought that nothingness is a problematic, perhaps even illogical, concept. ${ }^{1}$

\footnotetext{
${ }^{1}$ For Parmenides, see the discussion of Parmenides in the body of this article. Although the writings of Plato contain no explicit rejection of nothingness (except perhaps as he quotes Parmenides in the Sophist 237a), his principle of plentitude suggests a strong bias toward fullness and fecundity. (See Lovejoy 1960, 45-55) Aristotle rejected the idea of nothingness for several reasons, two of which concerned his theory of motion: (1) Since bodies fall toward the earth at speeds proportional to their weight and inversely proportional to the resistance (density) of the medium through which they fall, a body falling through a void would fall infinitely fast (would be described by a ratio whose denominator is zero), an absurdity in Aristotle's mind (Physics IV 215a 23-216a 11); and (2) Since void is nothingness, it would have no nature and thus no congeniality with bodies composed of earth, air, fire,
}

GRANDY, DAVID: Professor, Department of Philosophy, Brigham Young University, USA. Email: david_grandy@byu.edu 
How, after all, could one coherently insist on the existence of something that by definition does not exist, or at the very least cannot be empirically apprehended?

This point - that Western thinkers were uncomfortable with the idea of nothingness - is often made with reference to the grudging acceptance of zero in the West. Conceptualized in India, zero caught on quickly there but was often resisted in the West, even among thinkers who valued its mathematical utility. The notion of nothingness, which zero embodied, connoted negativity and lack, and they struggled to grasp what positive good could come of it. With respect to the introduction of zero into medieval Europe, Fabio Gironi writes: "Europe was still conceptually dependent on Aristotle - whose philosophy rejected the possibility of absolute void (nature itself was said to abhor vacuum) and infinity - and was preoccupied, theologically, with the fullness of being, relegating nothingness to the realm of Satan" $(2012,10)$. Offering another angle on the Greek wariness of any view invoking nothingness, John D. Barrow writes: "Strangely, the ancient Greeks, despite their extraordinary intellectual achievements, failed to make these basic discoveries [regarding zero]. Indeed . . . their approach to the world and their use of logic to unravel its workings was a serious impediment to the genesis of the zero concept. They demanded a logical consistency of their concepts and could not countenance the idea of 'Nothing' as something. They lacked the mystical thread that could interweave the zero concept into a practical accounting system" $(2000,48)$.

Things may have gotten off to an inauspicious start in the West with Parmenides, who appears to have insisted that while being is a changeless, tenseless whole, nonbeing could not exist, nor could it even be thought or spoken. Simplicius reports Parmenides as teaching: "Never was it [i.e., being], nor shall it be, since it now is, all together, one, continuous. For what birth would you seek of it? Where [or: how], whence did it grow? Not from what-is-not will I allow you to say or to think; for it is not sayable or thinkable that is not" (in Graham 2010, 216-17). Coming-into-being and growth implied emptiness or void which, owing to its nothingness, allowed change by offering no resistance to it, but how does one even begin to think and talk about nothingness?

This objection to nothingness evidently fell with less force upon Eastern thinkers, particularly Mahayana Buddhists who elaborated the doctrine of sunyata-the inherent emptiness of things - as a foundational principle of reality. In this case "foundational" does not imply bedrock or ultimate stability but rather self-collapsing insubstantiality and therefore ongoing impermanence or flux (annica). Sunyata is at once weightless and freighted with the virtual or near-virtual weightlessness of the world; hence all of reality is empty, open, and dynamically interactive. Or, in

or water; it consequently would have no ability to support their natural motion toward or away from the earth's center. Nor would it be able to support their unnatural or violent motion, since such is sustained as a projectile body cuts through a material medium, causing the medium to circulate around the body and push it forward from behind. (Physics IV 215a 1-18). 
Mahayana parlance, all is "co-dependently arisen" (pratītyasamutpāda) since any one thing is tenuously bootstrapped into existence by the courtesy of everything else.

In this article I wish to show that something like sunyata manifested itself in the thinking of Western philosophers-primarily Plato and Aristotle, but also the atomists as their ideas have been revised by modern science-even as they tried hard to avoid it. (In the case of the atomists this will involve showing that atoms have lost their erstwhile substantiality.) Unlike the Mahayanists, these thinkers felt themselves obliged to ground their explanations of reality to unchanging entities or principles, thereby laying down an ultimate safeguard against change. It seemed right to them that truth could not be subject to the vagaries of change which infected phenomenal reality; if that were the case, it would have no staying power and consequently no lasting efficacy - a very strange kind of truth and, arguably, not truth at all. The task of the Western thinkers then was to put change to rest by showing that phenomenal change issues up from unseen constancy.

It is interesting that as these thinkers pursued this goal their explanations of reality shaded off toward nothingness or emptiness; further, those explanations became strained and problematic as they edged toward emptiness, so much so that one might wish to question the Western assumption that the world ultimately reduces to principles that are at once transparently intelligible and absolutely unchanging. An inviting counterpoint is the Mahayana thesis that nothing at all ever settles down to stasis, ontologically, conceptually, or otherwise, and thus all things, owing to lack of stable structure, are sunya or empty of inherent essence.

A challenging aspect of this article relates to the meanings of nothingness and emptiness as they apply to the subject at hand. I thus begin with a brief discussion of key terms as a way of introducing larger conceptual issues.

\section{DEFINITIONS}

Two words, oudeis (nothing) and kenos (empty), mark the Greek struggle with nothingness. While Parmenides and Melissus appear to have ruled out the possibility of void or emptiness on grounds of its necessary non-existence, Leucippus and Democritus were the first to have argued that emptiness does not entail non-existence. According to Aristotle, they insisted that although emptiness is not real in the sense physical matter is real-because it lacks palpable materiality-it is nonetheless real. It exists where physical bodies do not, thereby allowing them to change and move. Thus the atomists introduced "a new conception of reality," Cyril Bailey stated, one that acknowledged the existence of a kind of counter-reality beyond the limits of sense experience $(1928,75)$. If atoms were to be active, penetrative, and constitutive

of all we sensibly experience (as the atomists claimed), something else had to lack these qualities in equal measure. Empty space or void had to exist, but only in a way that allowed changing material reality to stand forth as the cynosure of all eyes.

With the atomists, then, nothingness became something more than Parmenidean non-being; while still unexperienced in every way, it became the complement to everything we do experience, though necessarily a blank, empty complement that 
invited the charge of paradox. G.S. Kirk et al. suggest that the atomists executed a kind of doublethink while conceptualizing the void: "when a place is occupied by nothing, then insofar as the occupant - 'the empty' - is nothing it does not exist, but insofar as it occupies a place it does exist" $(1983,415)$. In any event it is easier to grasp why the atomists posited the void (to validate the testimony of sense experience within an atomistic framework, which testimony required that atoms move about in an expanse empty of atomistic being) than to know precisely what the void is supposed to be. It seems to be an emptiness that throws the fullness of material reality into relief. Unlike atoms, which cannot be subdivided in virtue of their monistic plentitude, void is completely empty of everything, except perhaps itself.

In sum, the atomists turned Parmenidean non-being into void, without which material atoms could not register their dynamical presence. As we shall see, Plato and Aristotle steadfastly resisted non-being, though they felt its tug while trying to work out elemental features of their world systems. It is almost as if non-being, by reason of its vacuum-like properties, draws material entities into its nihilistic embrace, depriving them of the substantiality they were once thought to embody. This reading, however, reflects the general Western antipathy toward nothingness. In the East the attitude was upbeat, even celebratory. Intimations of non-being pointed toward sunyata.

Sunyata refers to "the utter unfindability of objects" (Napper 1983, 4) - not, however, because objects manage to keep themselves hidden but because they lack inherent existence. "All things are empty," writes Elizabeth Napper. "Empty of what? Of being independent autonomous entities, of having some 'own thing', some intrinsic nature that comes from their own side without depending on external causes and conditions or on a subjective factor of those who observe them" $(1983,3)$. So emptiness ultimately coincides with what cannot be found despite the appearance of objective existence. Tables appear to be self-existing objects, but the appearance is deceptive because no table exists independently of its parts, and those parts are similarly composed of parts, and so on down. "At some point," writes Napper, "the conventional phenomenon drops away and one is left with only the absence of what was sought, with a mere vacuity that is emptiness" $(1983,4)$.

More generally, sunyata describes the unfindability of principles that we unwittingly reify and embrace in our quest for understanding. These might be universals which are thought to inform particular events - a universal fire or fireness informing the fire now warming my living room, say-or our sense of enduring self amid the flux of everyday life. Mahayanists argue that these principles, though seeming to exist on their own merits, lack inherent self-essence and thus are incapable of affording us release from fear and suffering. Put differently, they are not the substratum upon which to build an edifice of truth and liberation. There is no substratum, and even the rejection of substratum should not be taken as substratum. That is, we should not reify emptiness as a principle of liberation, for such reification, by replacing one metaphysical principle with another, reignites the mistaken belief that metaphysical reflection is the path to nirvana. 
Properly realized, sunyata leads to the "exhaustion of all theories" or realizations (Loy 1997, 20). It speaks to "the groundlessness of all experience, to "the emptiness of emptiness"' (Huntington with Wangchen 1989, 26). More than this, however, it cuts a middle path between metaphysical absolutism and metaphysical nihilism, which its advocates claim is fully consistent with the teachings of the Buddha in two respects: (1) the wholesale rejection of metaphysical speculation, which speculation re-enflames the desire to cling to something final and lasting; and (2) the indeterminancy that arises as one finds oneself suspended between two poles, the first (metaphysical absolutism) gifting the individual with the possibility of beatific eternality and the second (metaphysical nihilism) negating that possibility with its declaration of the insignificance of existential striving. It is this indeterminancy that keeps one open - that is, sunya - to the ongoing play of things, the irresolution of which coincides with the Buddha's disinclination to speculate on whether enlightened beings exist or fail to exist after death. Such speculation, it is thought, would have subverted the Buddha's soteriological aims by giving his listeners a metaphysical position to cling to, thus depriving sunyata of its saving efficacy.

Whatever the Buddha had in mind with regard to salvation or liberation, it was not beatific eternality; that is, the exaltation of self to a change-free plane of lasting bliss. The prospect of such exaltation reinforces and valorizes the notion of self, which idea, by spawning concern with the past and future, draws us away from the radiant, revelatory, unresolved, indeterminate immediacy of the present moment. This immediacy discloses that existence is not subject to existential or metaphysical closure of any sort; indeed this disclosure does not count as closure or finality. Things remain sunya; that is, empty of self-identity and "empty of emptiness."

This is not the end of the story, however. Inherently empty entities compel the realization that all things are co-dependently arisen. Since no one thing stands alone but tenuously depends on other things for its existence, all things are mutually implicated. And since this wide tangle of dependencies involves oneself, one can never adopt a disinterested, spectator-like stance toward them (although there may be the pretense of such). We are always in the mix, and a delicate, indeterminate mix at that. The realization that tables do not exist independently of their parts gives us no ground on which to stand, for this realization collapses under the weight of its own part-composed authority, just as all further realizations do. These are empty claims because, to follow Nancy McCagney, they are like empty space-“open, indeterminate," and void of any "determinate basis" by which we might distinguish between determinateness and indeterminateness (1997, 95). We might call this inevitability epistemic free-fall, though that again would probably lull us into the false security of epistemic stasis.

\section{THE HEART SUTRA AND THE BASIC PROBLEM IN THE WEST}

As a heuristic for motivating this study of Buddhist and Western thought with regard to emptiness, I begin with the Heart Sutra's suggestion that contemplation of reality sabotages the expectation of epistemic closure by stretching practitioners toward the 
prospect of inherent non-self: "Avalokiteshvara Bodhisattva, when practicing deeply Prajna Paramita, perceives that all five skandhas [the psychophysical elements which compose one's being] are empty and is saved from all suffering and distress" (in Soeng 2010, 7). ${ }^{2}$ Here the realization of emptiness counts as saving wisdom, and the remaining lines of the sutra explain, among other things, that form is indistinguishable from emptiness. I argue that certain Western thinkers grasped this thought as well, though they did not, like Avalokiteshvara and other Buddhists, regard it as a moment of release and enlightenment. Rather they struggled against it, militating as it did against their conviction that physical reality is grounded to unchanging principles which enable clear, determinate explanation. Their error, to borrow McCagney's description, is that they tried "to fix and thus falsify what is continuously changing. To fix the event with a word is to make it determinate (nimitta) and thus illusory, like a magic show. It is an attempt to make time stand still" (1997, 80).

Parmenides was probably the first to explicitly grapple with something like emptiness, and he dismissed it as non-existent-something that by definition could not exist and therefore could not be invoked to explain reality. He argued that nothing exists but being. Thales had earlier proposed that water was the fundamental principle, a view that echoed the old water cosmogonies and that coincided with the prevailing vision of nature which saw the world as an organism. Water is necessary for birth and growth, and it is clearly a versatile substance in that it can exist as liquid, vapor, and solid. Thales did not, so far as we know (the evidence is scanty), address the question of how water changed from one state to another, but it obviously did. Nor do we know whether he addressed the question of how water could become something that does not look or feel like water-fire, say. The appearance of such a substance, though, would seem to require the intermingling of at least two fundamental substances, each transferring some of its properties to the other to produce a mutually derivative substance. Change (as embodied by the exchange of properties) would thus figure into the production of this third substance-something, it seems, that could not occur if, in fact, only one substance existed.

In taking up this broad question of whether change can occur when just one thing exists, we prepare ourselves for Parmenides' revolutionary outlook. Thinking more generally than Thales, Parmenides appears to have identified the fundamental principle as being and then asked himself whether there could be a second principle. If so, it would have to be utterly different from being (so as not to be derivative of being), but such a principle clearly could not exist, for it would be non-being. What is more, it would be unknowable, "for neither could you know what is not (for it cannot be accomplished), nor could you declare it" (in Graham 2010, 212-13). ${ }^{3}$

${ }^{2}$ A slightly different and more complete version of the Heart Sutra may be found in Goddard 1970, $85-86$.

${ }^{3}$ Among both ancients and moderns, some understanding of Parmenides is refracted through Melissus, who appears to have thought of himself as Parmenides's disciple. But whereas Parmenides's position on being and non-being is slightly ambiguous, Melissus' stance is clearly articulated. Diogenes Laertius, for instance, reports that Melissus insisted that "the totality was boundless, unalterable, 
Thus, we are left with just one principle. And to invoke a metaphor, a recipe with just one ingredient cannot produce anything new, cannot effect or embody change. The recipe "Take sugar" goes nowhere. All one gets out of it is sugar. It takes at least two ingredients to produce something new or different, and Parmenides apparently realized, at least to his own satisfaction, that since reality consists of just one ingredient, things can neither come to be nor cease to be. Dismissing theories that incoherently (in his mind) posited multiple ingredients, he reportedly declared: "Only one tale is left of the way: that it is; and on this are posted very many signs, that whatis is ungenerated and imperishable" (in Graham 2010, 214-15).

Here is another analogy that illustrates the point. Pack a bottle chock full of sand or flour and shake it. If the bottle is absolutely full, nothing within it moves - nothing changes. For Parmenides, reality is packed chock full of being, and so nothing moves. Nothing can move or change because the only way that could happen would be if the second ingredient — non-being or emptiness - existed. But it would be absurd to assert the being of non-being.

Before dismissing Parmenides as pedantic and perverse, let us note that he helped establish a pattern of thought that Western culture would come to embrace. Reality cannot be a mélange of contradictions. It must make logical sense. And in talking about reality we have to get our language straight; we can't talk out of both sides of our mouths at once. We cannot, at one moment, say everything that exists is being, and then, at a later moment, say that non-being or emptiness also exists.

Among his many accomplishments, Parmenides caused others to think more critically about change and the reliability of the physical senses (sight, hearing, taste, etc.) whereby we experience change. Thereafter thinkers, believing change to be real, posited at least two substances as the basis of reality. But in the case of the atomists, this led to paradox. Upon proposing that reality consists of tiny material atoms, they reasoned that empty space or void - the absence of material reality-would have to exist so that atoms could move. Emptiness thus became a foundational principle of reality, one that allowed atoms to fly about, interact, and combine into the objects of our experience-rocks, chairs, and so on. Already reality seemed to straddle the divide between something and nothing.

\section{INTIMATIONS OF EMPTINESS}

The vision of atoms moving through a void is an obvious instance of material reality showing up within a milieu of emptiness. Without emptiness, the material universe would be a solid, immobile block, and atoms, if they existed, would be perfectly wedged together. For the atomists, this was unacceptable, and it is easy to appreciate their insight that, without the addition of nothingness or empty space, material reality would be held fast by its own monistic plentitude.

motionless, one thing alike, and full. There is no motion, but there seems to be" (in Graham 2010, 464$65)$. Whether Melissus adopted a more extreme position against change than Parmenides is unclear. 
Less obvious is the way nothingness or emptiness - or something akin to suchmanifested itself in the thinking of those who did not believe in material atoms and who, at the obvious level, shied away from the prospect of empty space. While these thinkers cannot be said to have embraced emptiness, they felt pressed, for one reason or another, to venture close to its edge. The result is often a balancing act between something and nothing.

The balancing act shows up in Anaximander's outlook. Shortly after Thales posited water as the fundamental substance, Anaximander countered with apeiron, a primordial substance or condition completely void of distinctive features and limitations. Translated as indefinite, indeterminate, and boundless, apeiron marks a state that, while empty of almost anything we may imagine, is full of everything that is not limited and defined. There are, for example, no rocks in the apeiron, for every rock we know or may imagine is bounded and defined by particular qualities, whether by size, age, color, texture, and so on. There is, however, a sizeless, ageless, colorless, textureless, limitless something in the apeiron (or constituting the apeiron), and this is the seedbed for our world of bounded objects and phenomena. Anaximander states that everything we know emerges from the apeiron and flourishes for a season as contraries change into one another. ${ }^{4}$

Our world, Anaximander seems to say, is a determinate thing sprung up from the indeterminate apeiron. It is shot through with distinctive qualities, so much so that we can hardly imagine a world that lacks such qualities. But, in fact, the real world - that is, first-order reality - is empty of limitation and differentiation precisely because its stock-in-trade is limitless profusion or superabundant plenitude. Emptiness obtains in the apeiron only if we try to inventory well-defined aspects of our experience-color, size, tone, texture, mass, and so on. Otherwise a kind of cosmic embarrassment of undifferentiated riches prevails. ${ }^{5}$

While Anaximander's outlook may seem fanciful, we should note that it follows the trajectory of scientific reasoning. In explaining color, say, we do not argue that the fundamental constituents of colored objects possess color. Rather we assume that those constituents - think of atoms - are void of color and that color slips into the world of experience at a higher level.

Discussing our inability to visualize atomic phenomena, Norwood Russell Hanson insisted that "electrons could not be other than unpicturable. The impossibility of visualizing ultimate matter is an essential feature of atomic explanation." And, epistemically speaking, there is a good reason for this. "What requires explanation cannot itself figure in the explanation." (Hanson 1965, 119-20). To say that a brick is red because its atoms (or subatomic particles) are red gets us nowhere because it begs the question of redness. The only way to get epistemic purchase on the world is to

\footnotetext{
${ }^{4}$ For ancient sources of Anaximander's views, see Graham 2010, 45-71.

${ }^{5}$ Aristotle offers two reasons for Anaximander's attribution of indeterminateness to the apeiron: (1) if it were like the determinate primary elements of this world (earth, air, fire, and water), it would, by reason of its infinitude, overwhelm them and thereby stifle their emergence; and (2) if it were not free of limitation - that is, inexhaustible - it would be unable to sustain the (endlessly) ongoing origination of things in this world. See G.S. Kirk, J.E. Raven, and M. Schofield 1983, 113-14.
} 
evacuate first-order reality of the sense-arresting qualities we discover in secondorder reality, and in modern physics this means a first-order reality more like Anaximander's apeiron than a world differentiated according to sight, sound, smell, texture, and taste.

As scholars have remarked, Anaximander's apeiron, or something like it, leaves its mark on later thinkers. ${ }^{6}$ In the Timaeus, one of his later dialogues, Plato talks of the receptacle, a kind of receptivity, he explains, "of all becoming - its wet-nurse, as it were" (49a, in Plato 1992, 1251). He admits that this is an obscure concept and likens it to wax that receives the impress of a particular object, fully taking on the form of the object without adding any quality of its own. It is a kind of malleable generality, void of particular qualities and therefore unable to do anything but receive and register other things. Owing to its featureless nature, it does not show up on its own-it is empty of appearance, of visibility born of distinct colors and shapes. "[I]f we speak of it as an invisible and characterless sort of thing, one that receives all things and shares in a most perplexing way in what is intelligible, a thing extremely difficult to comprehend, we shall not be misled," wrote Plato (Timaeus 51b, in Plato 1997, 1254).

Why would Plato feel pressed to posit the existence of the receptacle, which, by his own almost apologetic admission, is "characterless and invisible" and "extremely difficult to comprehend"? Because, evidently, he was concerned with phenomenal change, which he wishes to trace back to unchanging principles through the intermediary of a third thing. Earlier in the dialogue Plato talked of a god-like Demiurge entering a realm of chaotic matter. Being supremely good, the Demiurge organized a physical universe from this matter by patterning it after a perfect, eternal model. Because, however, the universe was merely a likeness or copy of the model, it could not share fully in its perfection.

Of themselves, the model and the copy do not suffice to account for what we see about us because while it is easy to grasp how one thing copies another, it is hard to understand how changeless, perfect being could participate in imperfect becoming. The two realms, being utterly different, would seem to be incommensurable unless some third agency enabled the impress of perfection on becoming so that perfection is imperfectly captured in the world of becoming. The receptacle is the site at which this transfer of perfection into imperfection occurs. It receives the impress of eternal forms and converts the impressions into sensible phenomena, without, however, adding any qualities of its own.

So when we see fire, say, we see an imperfect semblance of eternity-one which, Plato is quick to insist, is not something in and of itself. How could it be, given its changing nature? Not only does it change from moment to moment, it also, when "condensed and extinguished," changes into air, and this cycle of change entails water

\footnotetext{
${ }^{6}$ See, for example, Kahn 1994, 233. Kahn writes that Anaximander's "Boundless is in fact what we call infinite space, the antecedent for the atomistic void as well as for the Receptacle or Nurse of generation in Plato's Timaeus. But he adds that "this space [the Boundless] is not yet thought of in abstraction from the material which fills it." For Anaximander, that is, the Boundless is not something distinct from its contents; for Plato, the receptacle, though featureless, is different from what it receives.
} 
and earth as well (Timaeus 49c, in Plato 1997, 1252). When looking at fire, then, we have no warrant for claiming that fire is in front of us as a definite thing. It is merely a quality momentarily thrown up in the receptacle by the process of change, not something that merits designation as an enduring substance. Indeed, because none of the constituents of this world (the sphere of becoming) achieve stability, none should be designated as definite things, according to Plato: "For they get away without abiding the charge of 'that' or 'this,' or any other expression that indicts them of being stable." He then adds: "But that in which they each appear to keep coming into being and from which they subsequently pass out of being, that's the only thing to refer to by means of expressions 'that' and 'this." (Timaeus 49e-50a, in Plato 1997, 1252. Original emphasis). In other words, the receptacle is a definite thing, even though it lacks qualities and its nature is to have no nature. It is more real than that which it flawlessly brings to appearance, for it is the enabling agency - the "wetnurse" - of appearance.

The thread that links Anaximander to Plato is the sense that the distinctly particularized world of everyday experience emerges from non-particularity; further, that the matrix of becoming and ongoing differentiation lacks all of the sensible qualities commonly assigned to the present world. Hence for both thinkers phenomenal reality is given birth by non-phenomenal principles. In Plato's case (we know less about Anaximander) this is a response to the problem of change, a way of letting change emerge from a realm that ambiguously cuts a middle path between the eternal model and its imperfect copy. Accordingly, explanations geared to the determinate features of the imperfect copy cannot get traction on the characterless reality of the receptacle. This is why Plato struggles to explain the receptacle.

Even Aristotle, famous for opposing the idea of empty space, recognized in other contexts the need for indeterminate blankness to enable the presentation of particular things. Not unlike Plato's receptacle, Aristotle's prime matter is a kind of featureless scaffolding for the erection or reception of distinct qualities that only then show up as this or that particular element - earth, air, fire, or water. To vary the metaphor, prime matter is an absolutely neutral canvas marked by interrelated brush strokes. An array of strokes shows up as an image but only because an indeterminate canvas is already there to register the strokes as such. That is, a canvas empty of distinctive features and therefore perfectly able to throw the array of strokes into relief as a distinct image.

In this way prime matter receives adjectival qualities and unifies them as particular elements. And because those elements stand forth as individual things, it is easy to assume that they are fundamental reality - that in taking their measure we are touching bottom. But beneath the visible, tangible, audible world of physical elements, there is a silent, unseen, intangible emptiness or receptivity that allows these elements to snap into place, so to speak, as their respective qualities bundle together. 
Aristotle also argued that human perception depends in part on the soul's welcoming capacity to receive sense data from the outside world. ${ }^{7}$ The word welcoming is meant to suggest both the soul's congeniality to the phenomenal world and its readiness to receive that world. The word capacity reflects Aristotle's view that the soul is capacious in that it is empty of distinctive features that would impede its reception of sense data. Hence the soul's ability or capacity to take in the world arises from its like-like resonance with the world, although the soul is on the receiving end of this relationship. ${ }^{8}$ Hence its welcoming nature.

In parallel with his theory of perception, Aristotle's theory of knowing posits an aspect of the mind that "is, before it thinks, not actually any real thing" (On the Soul 429a 23-24, in Aristotle 1984, 682). ${ }^{9}$ Again, mind entails a capaciousness or receptivity waiting to be filled. Aristotle compared it to "a writing-tablet on which as yet nothing actually stands written" (On the Soul 430a 1-2, in Aristotle 1984, 683). Thus it is "nothing until it has thought," until its blank self-innocence has been marked by thought (On the Soul 429b 32, in Aristotle 1984, 683).

Here one is reminded of John Locke's query regarding the eye: if it were not selfblind, would it be able to see the world? Perhaps not, Locke proposes, for a selfseeing eye might see only itself $(1952,87)$. Aristotle seems to be saying something similar: a fully self-knowing, self-aware mind would be full of itself and therefore oblivious to the outside world. Hence, it cannot be, of itself, self-aware. It is a kind of indefinite blankness for the reception of definite ideas, and only as such ideas are mingled into its own vacant but receptive being does the blankness achieve definition and thus become self-aware. ${ }^{10}$

\section{WRESTLING WITH EMPTINESS}

In each of these thinkers - Anaximander, Plato, and Aristotle - we find intimations of emptiness, hints that emptiness, or something very close to it, plays a vital role in the

\footnotetext{
${ }^{7}$ I hasten to add that Aristotle also posits an active part of the mind, or one that is "what it is by virtue of making all things." This in contrast to the passive part, which is "what it is by virtue of becoming all things"- that aspect of the mind explained above. On the Soul 430a 14-19, in Aristotle, 1984, 684.

${ }^{8}$ Aristotle quotes Empedocles approvingly: "For 'tis by Earth we see Earth, by Water, Water, / By Ether Ether divine, by Fire destructive Fire, / By Love Love, and Hate by cruel Hate." He also cites Plato to the same effect: "In the same way Plato in the Timaeus fashions the soul out of his elements; for like, he holds, is known by like, and things are formed out of the principles or elements, so that soul must be so too." On the Soul 404b 13-18, in Aristotle 1984, 645.

${ }^{9}$ This is the "thinking part of the soul," says Aristotle, which, "while impassible" must be "capable of receiving the form of an object; that is, must be potentially identical in character with its object without being the object." On the Soul 429a 14-17, in Aristotle 1984, 682.

${ }^{10}$ There is, perhaps, an exception to this generalization. In Book XII of his Metaphysics, Aristotle attributes the operation of nature to the actuality of the Unmoved Mover, a being whose "thought thinks itself because it shares the nature of the object of thought" (1072b 19-21, in Aristotle, 1984, 1553). Although in the Metaphysics Aristotle does not address the question of whether human thought is similarly capable of fully enclosed self-reflection, his assumptions regarding potentiality and actuality (which humans fail to wholly achieve), and his explanations in On the Soul, suggest otherwise.
} 
operation of nature and in our apprehension of nature. This is not to say, however, that these men were comfortable with emptiness, or would agree that their thinking was marked by it. After all, Anaximander's apeiron may be grasped as overbrimming fullness - it is empty only in the sense that it lacks the meager (limited) offerings of ordinary reality. As for Plato and Aristotle, they seem to have been wrestling with the question of how one can have sure knowledge of things in a world that is, from all appearances, ever-changing. ${ }^{11}$ Certain, lasting knowledge of things is possible only if those things have fixed, unchanging properties. But nature, it seems, is flux; it is process, not a static state of being affording lasting characterization.

Not long after Anaximander put forward his theory, Heraclitus uttered his famous maxim: "Everything flows, nothing stands still." 12 A variant on this thought, also attributed to Heraclitus is, "One can't step in the same river twice" (in Graham 2010, 158-59). The traditional understanding of this statement, going back at least to Plato and Aristotle, is that because the river changes from moment to moment, it cannot remain the "same" river for more than the briefest of instants. At first blush, this makes sense, at least to most people, but deeper consideration brings to light a monumental difficulty: If the river changes from moment to moment, what warrant do we have for referring to it as a single thing - as if it somehow survives the moment-to-moment changes we attribute to it. There is no warrant if, in fact, everything changes at each instant. ${ }^{13}$ Rather than capitulate to Heraclitus on this point, Plato and Aristotle felt pressed to push back against the manifest change of nature.

Plato's receptacle may be understood as the site at which change is finally put out of play. Like a single substance from which different objects are continually refashioned, it remains itself while accommodating change at a higher level. A gold cube differs from a gold sphere in shape, but both are composed of gold, and both remain gold despite modifications of shape. The substance-gold, in this analogy"does not depart from its character in any way," says Plato but its plasticity allows for ongoing change - a succession of different shapes that might mislead us into believing that reality is nothing but change (Timaeus 50b, in Plato 1997, 1253). The analogy is not perfect because gold does show up on its own, while the receptacle has

\footnotetext{
${ }^{11}$ I take it as a given that a longstanding aim of Western philosophy has been to produce fixed explanations of reality which comport with its assumption of changeless principles governing the everchanging show of nature. This, at least, has been the conventional starting point for students of Western thought. For example, John McCumber has recently written: "Parmenides started this off. His Way of Truth, which never changed, was developed out of a love of unity, for something truly unified cannot change. . . . For Plato, the atemporal [unchanging] realm became a whole congeries of moral values. It was not merely one unity, but a whole set of them, the [unchanging] Forms. . . . Aristotle denied that there are two different worlds, one atemporal and the other full of things that change and become. But he still maintained, with Plato, that the true natures of things are unchanging. He thus came up with 'essences', the unchanging basic components of our changing world" $(2011,4-5)$.

${ }^{12}$ For this sentiment and variations thereon, see Graham 2010, 154-55.

${ }^{13}$ Such is the way Plato and Aristotle seem to have understood Heraclitus, as holding that "all things are changing all the time," a proposition which the two later thinkers deemed incoherent and incomprehensible. A more sympathetic, and perhaps more plausible, reading, allows that Heraclitus may have believed that a unitary principle regulates the flux of nature; or, stability at higher levels results from an equilibrium of tensions among opposites at lower levels. See Graham 2010, 135-36.
} 
no properties of its own, and thus is faultless in its capacity to throw other things into relief.

Those things, however, are not stable and so do not lend themselves to static or ultimate characterization, which Plato deemed a criterion for truthful explanation. All the same, the unchanging receptacle, by having no nature to participate in change while giving birth to it, constituted a deeper reality unmarked by change. It thus saved the quest for fixed truth by revealing change as derivative and phenomenal. The irony, of course, is that Plato finds it at the brink of nothingness.

Aristotle also appears to want to stabilize the flux of nature in order to arrive at immutable truth. His fundamental material elements - earth, air, fire, and water - are, by his own reckoning, mutable and therefore, it would seem, an unsuitable foundation for the erection of permanent truth. His solution is to go one level down-beneath the elements with their mutable qualities - where change cannot occur. This is the realm of prime matter, a changeless, featureless substance that trembles on the edge of nothingness. It must, nevertheless, be something; otherwise the different objects of the physical world would go unrealized, for there would be no scaffolding to accommodate their properties. What is worse, if it did not exist, the world would be awash in change and fixed truth would be impossible.

As Daniel Graham has persuasively argued, prime matter is a problematic idea, and he characterizes it as an inadequate and unconvincing response to Parmenides' claim that change is unreal. Recall that Parmenides insisted that being is immobilized or wedged tight by its absolutely monistic plenitude. While this view contradicts everyday experience, it nevertheless optimizes the prospect of fixed truth; how else might one offer a lasting explanation of the world except by invoking lasting - that is, unchanging - principles? The problem for Aristotle is that he believes in change, at least at the obvious, everyday level, but he also feels pressed-by the need for fixed truth - to posit an unchanging substratum to underlie everyday change. The strange result, says Graham, is that prime matter "can have no essence of its own" but rather is something akin to "pure indeterminancy" (1987, 227). It is almost as if nothing changes in the substratum because nothing is there in the first place. Indeed, according to Aristotle, prime matter does not exist on its own but only as it accommodates the mutable properties that compose the various objects of our experience. So prime matter's existence, depending as it does on that which it supposedly underlies and supports, is extraordinarily tenuous.

Are Plato and Aristotle being overly pedantic? I think not. They are wrestling with the age-old problem of explaining a world that, judging from its ever-changing appearance, does not fully lend itself to final explanation. To be sure, regularities of nature exist that do reduce to final explanation, at least at first blush, and these spark the thought that perhaps all of nature can be so reduced. More fundamentally, these regularities entrain the mind to regular, rational thought and thereby launch humankind's quest for philosophical and scientific understanding. ${ }^{14}$ All the same, not

\footnotetext{
${ }^{14}$ Plato writes: "the [creator] god invented sight and gave it to us that we might observe the orbits of intelligence in the universe and apply them to the revolutions of our own understanding. For there is a
} 
everything reduces to rule and explanation. Invariably there are glitches or anomalies that resist codification, and, if comprehensive explanation is the goal, one option is to put them to rest by fudging the difference between the observed operation of nature and a hypothetical nether-realm where things are said to exist, albeit often without the properties commonly observed in ordinary reality. As noted earlier, this strategy tends to populate the nether-realm with shadowy entities-colorless, odorless, tasteless atoms, for instance - but it is a tried and true path of science. These entities, to vary George Berkeley's characterization of the infinitesimals used in calculus - which he described as "evanescent Increments ... neither finite Quantities nor Quantities infinitely small, nor yet nothing" (1734) — are the ghosts of departed bodies. They have few if any of the properties of real physical bodies, but somehow they are just as real-perhaps more real.

\section{A SLIGHTLY DEEPER STORY}

Readers may still wonder if this is not, quite literally, much ado about nothing. Is the so-called problem of change really a problem? For Plato and Aristotle it was. Consider the following statement: the acorn became an oak tree. Judging from appearance, acorns are not oak trees, so it seems strange to say, in effect, that not- $x$ became $\mathrm{x}$ : a thing that was not an oak tree became an oak tree. Following Aristotle, most people today would say that an acorn is an oak tree in embryo, or in potentia. So unless the acorn is hindered in its development, it becomes an oak tree. This is a good initial response to the problem of change, but Aristotle felt pressed to take it further. He noted that previous thinkers had proposed that change occurs as opposites or contraries interact (Physics I 187a 10-28; 188a 18-29, in Aristotle 1984, 319-21).

Anaximander, for example, had heat and cold-contraries sifted out of the apeiron-effecting seasonal change by "pay[ing] restitution to each other for their injustice to each other according to the ordering of time" (in Graham 2010, 50-51). Summer occurs in response to winter, as a kind of correction to the cold of winter, and then, in response to the excess heat of summer, things swing back the other way. So one might say, as people often do, that one season became another season, a different season. But now we are back to saying that not-x became $\mathrm{x}$, and it is hard to see how heat, for instance, is cold in potentia. Or how any quality could transform into its polar opposite.

Here we are dealing with something more fundamental than acorns becoming oak trees, for acorns and oak trees are neither contraries nor elemental substances. Instead they are composite bodies that share many common qualities. To bring the problem of change into sharp focus, we must consider what occurs at the elemental level where, according to Aristotle, starkly opposite qualities offset each other. What Aristotle has in mind are two pairs of opposites: hot and cold, and wet and dry. These are the four elemental qualities, and they are coupled in four different ways corresponding with

kinship between them, even though our revolutions are disturbed, whereas the universal orbits are undisturbed." Timaeus 47b-c, in Plato 1997, 1250. 
the four material elements. Hot-dry, for instance, is the quality dyad characterizing fire, and when dry turns to wet, fire becomes air, which is characterized by the hotwet dyad. But this is where the problem of change registers most starkly, for, again, it is hard to see how any quality could become its polar opposite. If wetness is somehow hidden up in dryness, then how can dryness be considered a separate fundamental quality - that is, one utterly different from other qualities?

Aristotle did not believe that wetness is hidden up in dryness, at least not in the sense of there being some physical trace of wetness in dryness. He did remark, however, that contraries make sense only as they interrelate. Unfortunately, his examples in this regard do not pertain to the elemental level and so do not adequately explain how not-x can become x. For example, a sun-tanned person-say Socratesshows up against a crowd of pale people. Further, Socrates may have been pale at an earlier time. ${ }^{15}$ If this is the case, Socrates' skin color changed over time, and that change occurred against a backdrop of difference, whether the pale skin of other people or the erstwhile pale skin of Socrates himself.

The problem, however, is that Aristotle regards skin color as an accidental or incidental feature of a person. It is not to be equated with Socrates' essential identity, whose self-same nature grants him single self-same personhood throughout an entire lifetime of physical change. So the observation that Socrates changed in virtue of becoming sun-tanned merely begs the question of whether change can occur at an elemental level; at a level where one encounters primitive substances or qualities whose foundational immutability stabilizes the cosmos and thereby allows it to be lastingly explained. As initiated by the Greeks, science does not want to keep playing catch-up with an ever-changing reality. It wants a reality that holds still for explanation.

To be sure, wetness and dryness semantically depend on each other, but, given the putative integrity of Aristotle's elemental qualities - each being irreducibly different from the others - no physical mechanism can exist whereby dryness, say, becomes wetness. In the case of skin color, by contrast, change can plausibly occur because the qualities involved are not primitive and because there is an obvious physical backdrop or substratum to support the change. Once, however, Aristotle hits the physical bottom of his cosmos (the four elements, each characterized by a quality dyad), the substratum, if it is to exist at all, must become metaphysical or otherworldly. This is where that which is dry becomes wet, that which is hot becomes cold, and so on, albeit in a virtual, wraithlike way that somehow protects the elemental qualities from actual change.

Thus Aristotle, affirming change but aiming for immutable truth, gives us a changing physical cosmos while pushing the envelope of that cosmos toward emptiness. Similarly in Plato, the receptacle lies just beyond the horizon of physical being. Or better, like Aristotle's prime matter, it marks the horizon at which physical change edges into fixed metaphysical truth. Granted, change occurs at that horizon but it is not, strictly speaking, physical change, and so it can be put out of play as a

${ }^{15}$ I take this example from Graham 1987, 116, 122-23. 
phenomenon that would otherwise subvert our attempts to offer final and lasting accounts of the flux of nature.

\section{ATOMS, CHANGE, AND SUNYATA}

If we are looking for a satisfying solution to the problem of change, the early Western equivocation between something and nothing does not provide it. The solutions offered by Plato and Aristotle verge on incoherence. Both thinkers rejected the void or empty space as a feature of reality but then felt compelled to posit a sort of primordial nothingness - "pure indeterminancy" having "no essence of its own," as Graham puts it - as the thin air into which physical change could dissolve and disappear.

It may be argued that this has been the general trajectory of Western thought ever since the early Greeks recognized change as an epistemological problem. We keep looking for unchanging principles to fix and explain the flux of nature, but as we find these principles, or think we find them, they cut toward nothingness. A modern case in point is the scientific determination that ordinary objects ultimately consist of unseen particles whose combined size amounts to hardly anything at all. We now imagine chairs and tables as mostly empty space.

But at least subatomic particles are stable, one might argue, and thus they provide that long hoped-for safeguard against change, even if they are incredibly tiny and void of secondary qualities. ${ }^{16}$ This view, however, is difficult to defend in light of recent scientific experiments which indicate that unobserved (pre-measured) particles are even more empty and evanescent than previously supposed. Seventeenth-century physics asked its devotees to subtract color, sound, odor, and texture out of the world, positing that such qualities do not reside in the world's fundamental constituents. Still, some properties, such as position and momentum, were thought to inhere in those constituents in a context-independent way. We now know, however, that this is not the case. Unobserved particles do not possess determinate (well-defined) position and momentum properties (nor certain other properties once assumed to be intrinsic to particular kinds of particles); further, this indeterminancy is directly related to the experimental demonstration of entanglement between counter-propagating particles originating from a common event. Quantum-entangled particles remain timelessly interactive across arbitrarily large intervals. ${ }^{17}$ They are not the hard, static, contextindependent objects theorized by the Greek atomists and later reintroduced by Hobbes, Gassendi, Descartes, and Newton.

While this is a very surprising scientific development, my point, made in the interest of philosophy, is threefold: (1) Atoms and subatomic particles, the putative bedrock constituents of the modern Western worldview, have been emptied of

\footnotetext{
${ }^{16}$ Much of the appeal of atoms lay in their assumed changelessness. As late as 1885 Sir Lyon Playfair stated: "An established truth in science is like the constitution of an atom in matter-something so fixed in the order of things that it has become independent of further dangers in the struggle of existence." Basalla et al. 1970, 82.

${ }^{17}$ For an explanation of quantum entanglement, see Mermin (Jul 1981) and Grandy (Dec 2014).
} 
properties, so much so that now there is little or nothing to cling to as we try to visualize them; (2) This scientific emptying of properties, or scientific discovery of emptiness, motivates a provisional response to the question of how particles are able to interact across arbitrarily large intervals: Not bounded or limited by the kinds of characteristics that particularize and "confine" objects of everyday experience, they remain "open" and responsive to each other; and (3) Change, as far as we can see, is written into the play of nature-past the unchanging particles, so assumed, and toward a sunyata-like world where all things, owing to their inherent emptiness or openness, are delicately and dynamically interactive.

For Nāgārjuna, the primary architect of the Mahayana concept of sunyata, the ever-changing flow of reality issued up from the emptiness of things, which emptiness allowed for their mutual interpenetration and interdependent origination (pratītyasamutpāda). Things could not exist in a context-independent way because that would imply relationless existence - each thing absolutely cut off from all elseand this is contrary to experience. What we do experience we experience by means of relation, even if the relation merely connects knowing subject and known object. But what is more, Nāgārjuna proposed that relations are empty or open conduits along which the emptiness of various relata can flow back and forth. If a relatum were not empty but full of its own nature and therefore impervious to outside flow, it would be cut off from all else and consequently unknowable. Finally, Nāgārjuna observed that something full of its own nature would be held fast by its own monistic plentitude and therefore be unable to change. "If all this is nonempty, ... There would be no arising or ceasing" $(1995,70)$. Things, in brief, have to be sunya or open to each other for the world to be the way we know it to be-in continuous flux and knowable, at least in the pre-theoretical sense that it is a matter of experience.

Displaying a more subtle grasp of the issues than Parmenides and those who followed him in his dichotomization of being and nonbeing, Nāgārjuna proposed a Middle Way between the two. The key understanding here is sunyata, which turns aside devotion to all intellectual understandings. Even those who devote themselves to sunyata are, according to Nāgārjuna, incurably misguided, for the Buddha, acting from compassion but fearing that his hearers would fixate on his views, taught the abandonment of all views $(1995,36) .{ }^{18}$ It is not the case that if being exists, nonbeing cannot exist, as Parmenides proposed, but that being and nonbeing exist in opposition to each other and so each exists indeterminately in an on-off sort of way that thwarts intellectual grasping and closure. ${ }^{19}$ Here is how Emmanuel Levinas, working along a non-Buddhist trajectory, put it: "The absence of everything returns as a presence, as the place where the bottom has dropped out of everything, an atmospheric density, a plentitude of the void, or the murmur of silence. There is, after this destruction of things and beings, the impersonal 'field of forces' of existing" (1990, 46).

\footnotetext{
${ }^{18}$ Nancy McCagney translates the relevant passage thus: "The conquerer taught openness as the refutation of all views. But those who hold openness as a view are called irremediable" $(1997,169)$.

${ }^{19}$ Speaking of sunyata, C.W. Huntington, Jr. writes: "Most contemporary scholars believe that the term emptiness refers neither to existence nor non-existence, and this is certainly the position I favor" $(1989,18)$.
} 
Aphoristically, presence and absence, existence and non-existence, lean into each other, indeterminately so.

In the West we have had to learn this the hard way. Thanks largely to science we have overcome our general antipathy toward the void and come to accept it as something that cannot be blithely written off as non-existent. The same is true of zero, negative numbers, and complex numbers involving the square root of -1 , all of which once struck Westerners as unreal owing to the absence of physical referents. (How, say, can you have negative five apples?) But there are other, more longstanding issues appertaining to the question of being and nonbeing which, it seems, never get resolved: they swing back and forth in a dialectical manner, first motivating one understanding and then motivating a different, perhaps antithetical understanding. Take, for example, the great debate on the question of space between Isaac Newton and Gottfried Leibniz, the former insisting that space is objectively real and the latter countering that it is nothing more than a relational artifact of our perception of various bodies, something brought into "existence" in the same way a family tree is brought into existence when one arranges one's ancestors in tree-like fashion (Alexander 1998). Is space real or an artifact of our pre-conceptual apprehension of nature? I believe Nāgārjuna would regard the question as sunya: this is not an eitheror proposition but one in which neither thesis can settle down to truthful stasis owing to its dependence on the other. Better then to remain interested in the question while eschewing attachment to either position: this is Nāgārjuna's Middle Way, which he claims is consistent with the teachings of the Buddha.

As noted above, the early atomists were among the few in the West to embrace the idea of emptiness. But they did not, like Nāgārjuna, go the full distance with the concept. What counts as full distance? I would say the willingness to let "the bottom fall out of the bucket" rather than positing metaphysically dubious entities (like selfexistent atoms, Plato's receptacle, or Aristotle's prime matter) to function as a bottom. In brief, no substratum, no safety net to catch changing entities as they fall toward groundlessness.

Lucretius, a Roman atomist, wrote: "If void did not exist, there is no way things would be able to move" $(2003,10)$. Lucretius surmised that change could not occur without emptiness, for emptiness allowed material atoms to get out of their own way, so to speak. But the snag here from a Mahayana perspective is that each atom is a tiny unchanging world, a Parmenidean whole protected from change by its monistic plentitude and perfect self-containment. Why, one might ask, should nature conspire to halt the flux of reality at the atomic level? Or at any level at all? Of course things might have been set up this way, but the work of the Western thinkers surveyed here, all united in their hope of arresting change, indicates that change cannot be put out of play, though it does slope off toward sunyata-like emptiness.

\section{ACKNOWLEDGEMENTS}


I thank Daniel Graham for helpful suggestions on an earlier version of this article. I also thank two anonymous referees at the journal Comparative Philosophy.

\section{REFERENCES}

Alexander, H.G. (ed.) (1998), The Leibniz-Clarke Correspondence (Manchester, UK: Manchester University Press).

Aristotle, On the Soul (trans. J.A. Smith), in Jonathan Barnes (ed.) (1984), The Complete Works of Aristotle, vol.1 (Princeton, NJ: Princeton University Press), 641-92.

- Physics (trans. R.P. Hardie \& R.K. Gaye), in Jonathan Barnes (ed.) (1984), The Complete Works of Aristotle, vol. 1 (Princeton, NJ: Princeton University Press), 315-446.

- Metaphysics (trans. W.D. Ross), in Jonathan Barnes (ed.) (1984), The Complete Works of Aristotle, vol. 2 (Princeton, NJ: Princeton University Press), 1552-1728.

Bailey, Cyril (1928), The Greek Atomists and Epicurus (Oxford, UK: At the Clarendon Press).

Barrow, John D. (2000), The Book of Nothing: Vacuums, Voids, and the Latest Ideas about the Origins of the Universe (New York: Pantheon Books).

Basalla, George, William Coleman, and Robert H. Kargon (eds.) (1970), Victorian Science: A Self-Portrait from the Presidential Addresses of the British Association for the Advancement of Science (Garden City, NY: Anchor Books).

Berkeley, George (1734), The Analyst, ed. David R. Wilkins. At $<$ http://www.maths. tcd.ie/pub/HistMath/People/Berkeley/Analyst/Analyst.html> 20th June 2012.

Gironi, Fabio (2012), "Śxunyatā and the Zeroing of Being: A reworking of empty concepts", Journal of Indian Philosophy and Religion, 15: 1-42.

Goddard, Dwight (ed.) (1970), A Buddhist Bible (Boston, MA: Beacon Press).

Graham, Daniel W. (1987), Aristotle's Two Systems (New York: Oxford University Press).

- (trans. \& ed.) (2010), The Texts of Early Greek Philosophy: The Complete Fragments and Selected Testimonies of the Major Presocratics, Part I (Cambridge, UK: Cambridge University Press).

Grandy, David (2014), "Sunyata and Self-Empty Particles," Journal of Indian Philosophy and Religion, 19: 46-61.

Hanson, Norwood Russell (1965), Patterns of Discovery: An Inquiry into the Conceptual Foundations of Science (Cambridge, UK: Cambridge University Press).

Huntington, C.W., Jr. with Geshé Namgyal Wangchen (1989), The Emptiness of Emptiness: An Introduction to Early Indian Madyamika (Honolulu, HI: University of Hawaii Press).

Kahn, Charles H. (1994), Anaximander and the Origins of Greek Cosmology (Indianapolis, IN: Hackett Publishing Company). 
Kirk, G.S., J.E. Raven, and M. Schofield (1983), The Presocratic Philosophers, $2^{\text {nd }}$ edition (Cambridge, UK: Cambridge University Press).

Levinas, Emmanuel (1990), Time and the Other (trans. Richard A. Cohen) (Pittsburgh, PA: Duquesne University Press).

Locke, John (1689), An Essay Concerning Human Understanding, in R. M. Hutchins (ed.) (1952), Great Books of the Western World, vol. 35 (Chicago: William Benton).

Lovejoy, Arthur O. (1960), The Great Chain of Being: A Study of the History of an Idea (New York: Harper \& Row).

Loy, David (1997), Nonduality: A Study in Comparative Philosophy (Amherst, NY: Humanity Books).

Lucretius (2003), On the Nature of Things (trans. Walter Englert) (Newburyport, MA: Focus Publishing).

McCagney, Nancy (1997), Nāgārjuna and the Philosophy of Openness (Lanham, MD: Rowman \& Littlefield).

McCumber, John (2011), Time and Philosophy: A History of Continental Thought (Montreal: McGill-Queen's University Press).

Mermin, N. David (1981), "Quantum Mysteries for Anyone," The Journal of Philosophy, 78 (7): 397-408.

Nāgārjuna (1995), The Fundamental Wisdom of the Middle Way: Nāgārjuna's Mūlamadhyamakakārikā (trans. \& comm. Jay L. Garfield) (New York: Oxford University Press).

Napper, Elizabeth (2003), Dependent-Arising and Emptiness (Boston, MA: Wisdom Publications).

Plato, Timaeus (trans. Donald J. Zeyl), in John M. Cooper (ed.) (1997), Plato: Complete Works (Indianapolis, IN: Hackett Publishing Company).

Soeng, Mu (2010), The Heart of the Universe: Exploring the Heart Sutra (Somerville, MA, Wisdom Publications). 